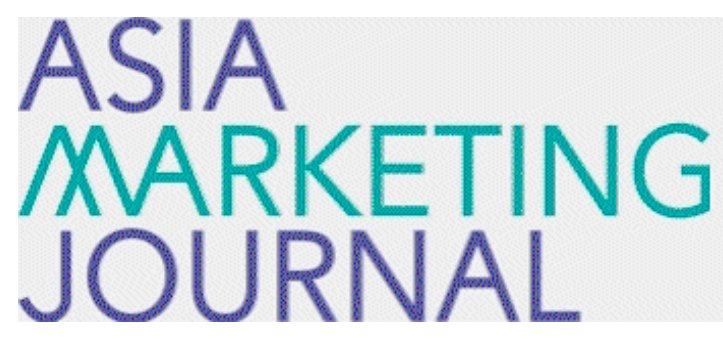

ASIA MARKETING JOURNAL

Volume 23 | Issue 4

Article 2

February 2022

\title{
Donation Levels in Cause-Related Marketing (CRM): The Impact of Donation levels, Consumer Support and Self-Expressive Cues on Perceived Benefits and Perceived Monetary Sacrifice
}

Tae Hee Park

Chung-Ang University, Seoul, Korea, taeheepark@hanmail.net

Dongho Yoo

Global Business School, Halla University, Wonju, Gangwon, Korea, dongho.yoo@halla.ac.kr

Follow this and additional works at: https://amj.kma.re.kr/journal

Part of the Advertising and Promotion Management Commons, E-Commerce Commons, Marketing Commons, and the Other Business Commons

\section{Recommended Citation}

Hee Park, Tae and Yoo, Dongho (2022) "Donation Levels in Cause-Related Marketing (CRM): The Impact of Donation levels, Consumer Support and Self-Expressive Cues on Perceived Benefits and Perceived Monetary Sacrifice," Asia Marketing Journal: Vol. 23 : Iss. 4 , Article 2.

Available at: https://doi.org/10.53728/2765-6500.1580

This Article is brought to you for free and open access by Asia Marketing Journal. It has been accepted for inclusion in Asia Marketing Journal by an authorized editor of Asia Marketing Journal. 


\title{
Donation Levels in Cause-Related Marketing (CRM): The Impact of Donation levels, Consumer Support and Self-Expressive Cues on Perceived Benefits and Perceived Monetary Sacrifice
}

\author{
Tae Hee Park ${ }^{a}$, Dongho Yoo ${ }^{\text {b,* }}$ \\ ${ }^{a}$ Consumer and Advertising Psychology, Chung-Ang University, Seoul, South Korea \\ ${ }^{\mathrm{b}}$ Global Business School, Halla University, Wonju, Gangwon, South Korea
}

\begin{abstract}
In this study, we examine the extent to which donation level is perceived as a concept of benefit and monetary sacrifice to consumers, as well as that the extent to which it is moderated by consumer support for cause domains. In addition, we investigate the influence of self-expressive cues as a means of increasing consumers' intention of participating in causerelated marketing (CRM) by lowering perceived monetary sacrifice. As a result of Study 1, consumers with high-level cause support perceived the donation level as a benefit, resulting in a positive effect on their intentions to participate in CRM. Conversely, consumers with low-level support perceived the donation level as monetary sacrifice. Thus, donation level had a negative effect on their participation intentions. Study 2 showed that self-expressive cues dilute the interaction effect of donation levels and consumer support. We conclude by discussing the academic and practical implications of this study.
\end{abstract}

Keywords: Cause-related marketing, Donation level, Consumer support, Self-expressive cues, Perceived benefits, Monetary sacrifice

\section{Introduction}

s consumer demand for management that
contributes positively to the communities in
which firms operate increases, interest in corporate
social responsibility (CSR), the core of sustainable
management, has also seen an increase (Yoo and
Lee 2018). As a result, companies are using methods
that contribute to society in various ways, of which
cause-related marketing (CRM) is the most repre-
sentative and practical form of CSR (Kuo and Rice
2015; Seo et al. 2020; Yoo et al. 2018). CRM is a CSR
strategy that connects consumers purchases and
donations. For example, Tommy Hilfiger launched a
CRM campaign to donate $50 \%$ of the product price
to Breast Health International, and Starbucks
donated $\$ 1$ per pound of coffee to a global fund to
support AIDS patients in Africa. In 2018, companies spent nearly $\$ 65.8$ billion worldwide on CRM (Statista 2018).

Companies are running campaigns with a constant focus on CRM because of the belief that CRM not only improves society, but also drives positive responses from consumers. Consumer demand for corporate CRM practices is always high (Coleman et al. 2020). Indeed, it is known that about $90 \%$ of consumers want a company to contribute to society (CauseGood 2017). Previous research has also shown that consumers prefer companies that contribute to the development of society and act in a manner that is socially responsible (Landrum 2017). However, previous research has not given clear results on the effectiveness of a company's investment in CRM (Müller et al. 2014). On the one hand, donation through consumer purchases allows consumers to experience positive affect known as

Received 10 October 2021; accepted 13 December 2021.

Available online 3 February 2022.

* Corresponding author.

E-mail addresses: taeheepark@hanmail.net (T.H. Park), dongho.yoo@halla.ac.kr (D. Yoo). 
"warm glow" (Andreoni 1989), which leads to favorable purchasing behavior. On the other hand, donation of CRM presupposes consumer purchasing behavior and guarantees the interests of the company, which can lead to consumer doubts about a company's motive (Barone et al. 2000). This negatively affects corporate image, and as such, provides an incentive for companies to consider how to increase efficiency beyond CRM implementation.

According to previous research, several factors can affect whether the impact of CRM is positive or negative (Fries 2010). In this study, we focus on the role of donation level as a factor that can affect the success of CRM. In CRM, the donation level is a design element that companies can control directly by setting donation levels at various amounts (Müller et al. 2014). For example, P\&G set their donation level to $1 \%$ of the retail price of their products, while Tommy Hilfiger set their donation level to $50 \%$ of their product prices to launch a CRM campaign. However, there is a lack of academic interest in what level of donation is appropriate. In addition, the donation level affects consumer perception regarding the positive aspects of a campaign along with consumer perception of negative aspects, such as monetary sacrifice (Yoo et al. 2018). Therefore, it is very important for successful CRM to see when donation levels are perceived positively and negatively by consumers. Unfortunately, previous studies did not delve into this particular facet of CRM. In this study, we investigated consumer perception of donation levels in CRM, and proposed consumer support for the cause domain presented to them as a key variable. Specifically, based on a previous research (Winterich and Barone 2011) that consumer support for cause domains allows consumers to focus on the cause domain itself by activating their social identity and improving consumer-company identification, we predicted that high-level consumer support would make them perceive the donation level as a benefit rather than a monetary sacrifice.

In addition, we investigated how to reduce consumer perception of monetary sacrifice apart from when consumers perceive the donation level as a benefit or monetary sacrifice. Specifically, we looked at whether self-expressive cues that lead consumers to manage their impressions (Kristofferson et al. 2014) reduce perceived monetary sacrifice. We expect self-expressive cues to focus consumers on the positive aspects of CRM.

The purpose of this study is to see if consumer perception of donation level as a CRM tool is determined by consumer support. Previous studies have shown that donation level has both positive and negative impacts on consumer responses, though such studies have tended to lack interest in what determines such consumer responses. We proposed that the impact of donation level depends on consumer support for the cause domain, and examined the mediating roles of perceived benefits and perceived monetary sacrifice. Additionally, we investigated the role of self-expressive cues as a way to increase intentions to participate in CRM by lowering consumer perception of monetary sacrifice. The results of this study are expected to not only provide a mechanism through which to examine the effect of donation levels on CRM, but also to provide practical implications for the successful implementation of CRM by companies.

\section{Theoretical background}

\subsection{Cause-related marketing (CRM)}

Stakeholders are putting increasing pressure on today's companies to employ approaches to governance that go beyond mere profit maximization (McWilliams and Siegel 2001). CSR refers to the efforts of a company to utilize its strengths to minimize negative impacts on society while maximizing its positive impacts (Mohr et al. 2001). CSR is perceived as an important component to corporate survival and long-term growth (Mohr and Webb 2005). In other words, CSR is the most fundamental element of a company's sustainability-related activities (Yoo and Lee 2018).

Types of CSR include CRM, community sponsorship, and various eco-friendly activities (Kotler and Lee 2008; Sen and Bhattacharya 2001). Among them, CRM refers to a company's use of a certain percentage of a product's retail price to solve social issues or donate to a non-profit organization (NPO) (Grau and Folse 2007). CRM differs from other approaches to CSR in that corporate social activities are directly linked to the sale of products. Thus, CRM is the most practical form of CSR (Yoo et al. 2018).

For companies, CRM is an effective marketing tool that can achieve two purposes: increasing sales and generate positive responses from consumers (Lee 2017; Lee and Yi 2017). Previous research has shown that CRM has a positive effect on consumer purchasing intentions and attitudes toward companies, products, and brands (Berger et al. 1999; Chen et al. 2014; Moosmayer and Fuljahn 2010). Furthermore, CRM is a catalyst for customer satisfaction in that it allows customers to take heart in the fact that they have participated in donation activities and 
provided help to others by purchasing products through CRM (Andrews et al. 2014). In other words, CRM is a marketing strategy that can satisfy both companies and consumers.

\subsection{Donation level}

In CRM, companies agree to donate a predetermined percentage of their revenue as a means of incentivizing consumers to participate in sociallyresponsible activities and purchasing products (Grau and Folse 2007). The donation level presented to consumers through CRM represents the extent of the benefits to society (Grau and Folse 2007; Polonsky and Speed 2001). This donation level is different from other elements of CRM in that it is a design element that can be directly controlled by the company (Müller et al. 2014). According to previous research, donation level is a very important factor in the response of consumers to CRM participation (Yoo et al. 2018).

What level of donation is most effective in CRM campaigns? In this regard, previous research has shown that donation levels have both positive and negative effects on consumer CRM participation. Prior studies showing the positive effect of donation levels confirmed that the higher the donation level, the more consumers experience warm glow through participation (Andreoni 1989), which leads to more positive purchase intentions. These studies suggest that the higher the donation level, the more likely consumers are to think that the CRM campaign was effective (Hajjat 2003) and that the intention of the company carrying out the CRM was pure (Dahl and Lavack 1995). Conversely, prior studies showing the negative effects of donation levels have mainly addressed the aspect of the cost consumers have to pay (Yoo et al. 2018). The high level of donation in CRM increases the financial burden of consumers, which, in turn, lowers their intention to participate in CRM. For example, Chang and Lee (2008) investigated differences in consumer preference for donations and discounts. According to their research, when the amount of donations and price discounts presented to consumers was low, consumers tended to prefer donations over price discounts, but when the amount was high, they preferred price discounts to donations. The amount presented at a high level makes consumers more likely to perceive their contributions as a monetary sacrifice, and as a result, consumers are more influenced by self-interest than altruism related to donations. In addition, by increasing donation levels, firms contribute to a consumer perception that leads to consumer burden while guaranteeing company profits, leading to consumer doubts about a company's motives (Barone et al. 2000). In other words, the donation level has a negative effect on consumer purchase intentions or willingness to participate in CRM.

In summary, consumers exposed to donationrelated information in CRM experience both the positive emotion of altruism via their ability to help others, and negative emotions relating to sacrificing more money (Strahilevitz 1999). In a similar vein, Howie et al. (2018) showed that the level of consumer engagement in CRM may be perceived as a benefit, but also as a cost to be paid. More directly, Yoo et al. (2018) recently mentioned that donation levels in CRM can be perceived by consumers in two different forms: benefits and monetary sacrifice. If consumers perceive the donation level as a benefit, the donation level has a positive effect on their intention to participate in CRM, but if they perceive the donation level as monetary sacrifice, the donation level negatively affects consumer intentions to participate in CRM. This means that the impact of the donation level in CRM depends on the manner in which consumers perceive the donation level itself.

\subsection{Consumer support}

In general, consumers are positively aware of corporate social activities (Sen and Bhattacharya 2001), though this positive perception may vary depending on their attitude toward the cause domain. Previous studies have explained this through consumer support, which is defined as the degree to which consumers support a specific cause domain executed by a company (Sen and Bhattacharya 2001). High consumer support means that consumers share common values with companies (Sen and Bhattacharya 2001; Yoo and Lee 2018). In the context of CRM, we have defined consumer support as the level of backing for the donation areas presented in CRM. Consumer support is subjective and influenced by a variety of factors because it reflects the consumer's personal approval of a particular initiative. For example, previous research has stated that consumer support is influenced by familiarity with the cause (Drumwright 1996), personal relevance (Creyer and Ross 1997), and self-importance (Haley 1996; Sen and Bhattacharya 2001).

Consumer support has a positive effect on consumer evaluations of a company as well as prosocial behavioral intentions. Consumers want companies to be socially responsible and put pressure on companies to conduct pro-social activities, such as 
ethical consumption and ethical purchasing. At this time, consumer support serves as a reference point that determines the attitude or behavior of consumers toward a company (Creyer and Ross 1997; Powell et al. 2007). Consumers compensate or punish companies based on the extent to which they do or don't support a cause, respectively (Creyer and Ross 1997), with the higher levels of support leading consumers to perceive a given company as behaving more responsibly. In a similar vein, Mohr and Webb (2005) found that when consumers have high support for CSR activities, its effect on their purchase intentions was greater. According to Marin and Ruiz (2007), the greater a consumer's support for the cause domain, the more they identify with a company, which leads to higher corporate value. In other words, when a consumer's level of support for a specific cause domain is high, they have a positive attitude which is manifested in their intention to act, but when their support level is low, they have a negative attitude and are disincentivized from acting.

As mentioned earlier, consumer support has a positive impact on consumer evaluations. However, in this study, we expect that consumer support not only influences consumer responses, but also affects the way consumers process information. Specifically, we expect consumer support to affect consumer perceptions of donation levels as being benefits or monetary sacrifices. This is because consumer support affects a consumer's social identity perceptions as well as the consumer's ability to identify with the company. According to previous research, the cause suggested in CRM becomes a cue that awakens the social identity of consumers (Reed 2004), and this social identity becomes more active when the presented cause matches the interests of target consumers (Winterich and Barone 2011). In other words, high-support consumers who perceive that they share values with a have a greater degree of social identity than low-support consumers (Yoo and Lee 2018). As a result, they consider the cause area itself rather than other factors and focus more on the purpose of the cause. For example, according to Marin and Ruiz (2007), consumers with high support are more impacted by CSR than attributes such as the capability of a company (CA), resulting in a more positive evaluation of the company as CSR levels increase. Yoo and Lee (2018) also revealed that when consumers express high-level support, they positively evaluate companies regardless of the fit between the company and cause domains and the consistency between cause domains. This means that consumers with high support for the cause domain focus on the goals and benefits of donations presented in CRM. Therefore, it is expected that the higher the donation level, the more they perceive the benefits of CRM.

Furthermore, consumer support is known to increase identification between consumers and businesses. According to previous research, identification of consumers and companies emphasizes the positive aspects and weakens the negative aspects of a company. As a result, consumers evaluate corporations positively and exhibit high brand loyalty and resilience to negative factors associated with a company's brand (Baskentli et al. 2019; Bhattacharya et al. 2011). This means that consumers with high-level support will focus more on the purpose of the campaign and its positive aspects than the negative aspects associated with donation when exposed to CRM campaignrelated information. Therefore, we expect consumers with high support for the cause domain to perceive the donation level as beneficial rather than a monetary sacrifice, and the donation level as having a positive effect on a company's intentions to participate in CRM. Thus, we present Hypothesis 1 as follows:

H1. Compared to consumers with low support for the cause domain, consumers with high support will perceive more benefits as the donation level increases.

However, consumers with low support for the cause domain will judge that the cause as not having met their internal reference, which will lead them to seek additional information that is unrelated to the cause (Maity et al. 2014; Yamamoto et al. 2014). In addition, they are likely to doubt the motivation of a company to implement the cause (Yoo and Lee 2018). The search for additional information and doubts about corporate motivation lead consumers to consider monetary costs as opposed to benefits (Habel et al. 2016). In a study by Habel et al. (2016), consumers who suspected a company of having ulterior motives with respect to their CSR initiatives tended to think of the company's CSR as a factor of price increases rather than as a net benefit, resulting in an unfair perception of the company's price. In a similar vein, Lafferty (1996) demonstrated that large donations have a rather negative effect if the proposed cause activities were perceived as not important to the consumer. Therefore, we expect consumers with low support for the cause domain to perceive the donation level as a monetary sacrifice, as opposed to a benefit, with the donation level having a negative effect on the consumer's intentions to participate in CRM. Based on this, we derived the following hypothesis: 
H2. Compared to consumers with high-level support for the cause domain, consumers with low support will perceive more monetary sacrifice as the donation level increases.

Finally, we expected that consumer intentions to participate in CRM would vary depending on the level of donations and consumer support. Specifically, for consumers with high support who perceive the donation level as a benefit, the donation level should have a positive effect on consumer participation intentions. However, for those with low support who perceive the donation level as monetary sacrifice, the donation level will have a negative effect on CRM participation intention. Through this, we derive the following hypothesis:

H3. Consumers with high-level support for the cause domain will have positive intentions to participate in CRM as the donation level increases, while those with low-level support will have negative intentions to participate in CRM.

H4. The effects of donation levels and consumer support on intentions to participate in CRM will be mediated by perceived benefits and perceived monetary sacrifice.

\subsection{Self-expression}

People intrinsically try to express their thoughts or identity. Self-expression refers to the inner motive that people seek to improve or develop themselves by expressing "self" (Gentina et al. 2017). They specifically construct their own personal thoughts and emotions through self-expressive behavior (Kim and Sherman 2007). At the same time, people try to maintain interpersonal relationships by sharing and communicating their thoughts and identities with others. Self-expression also includes emotional advantages (Martínez and Montaner 2006), which are realized by controlling the manner in which one person is perceived by others (Berger and Heath 2007; Chan et al. 2012; Elliott 1997; Leary and Kowalski 1990; Rifkin and Etkin 2019; Sela and Maimaran 2013; White and Dahl 2006, 2007).

Consumers also express themselves through the purchase of products or brands, as the ownership of a product or brand conveys much about their identity as a result of the messages that are associated with that good (Saenger et al. 2013). Consumers use purchases to provide insights about their true nature to others (Belk 1988) as well as clues about their ideal selves (Ahuvia 2005), such as membership in an exclusive group (Escalas and Bettman 2005). They also use conspicuous consumption in the interest of self-expression to expose their income or wealth to others (Chernev et al. 2011). The purchase of products with socially-desirable meanings serves a similar purpose. Consumers try to express their ethical or moral ideals to others by purchasing products related to CSR or CRM (Aquino and Reed 2002; Huang et al. 2017).

According to Jeong et al. (2013), when a CRMrelated post is presented on the Facebook brand fan page, the participants were more likely to click the "Like" button and share the post with their friends as a means of enhancing their own image in the eyes of others.

Consumer self-expressive behavior occurs more frequently when self-expressive cues that reveal thoughts or actions to others are presented. Selfexpressive cues make consumers care about their impressions of others and promote behaviors that have a positive impact on impression management (Kristofferson et al. 2014). For example, Facebook serves as a self-expression cue that allows users to reveal their self-identity to others. As a result, users take more care to make the image that they project to others in a social networking context positive than they do with their real-life personas. Indeed, according to Rajaguru and Ganegoda (2017), users are more pro-social on Facebook than they are in real life. However, most of the users who have engaged in pro-social behavior on Facebook did not act in such a manner in real life. In addition, Hollenbeck and Kaikati (2012) suggested that Facebook users tend to post their appearance or brand image on their profile page, which, if done well, allows other people to form positive impressions about them. This means that consumers utilize more selfexpressive behavior and impression management when self-expressive cues are presented.

In the context of CRM, we expect that the effect of the interaction between donation level and consumer support on consumers' reactions will be diluted in situations where self-expressive cues are presented. As mentioned earlier, when self-expressive cues are presented, consumers focus on managing their impressions of others (Kristofferson et al. 2014). At this time, participating in CRM can be a good alternative to positively-recognizing their image with others. Donation through CRM becomes a means to express one's ethics and morality to others (Aquino and Reed 2002; Huang et al. 2017). Consumers express their social identities by performing socially-desirable behavior through CRM (Reed 2004). In addition, a high donation level conveys the message that an individual is making more effort for others. In other words, when selfexpressive cues are presented, CRM is perceived as 
a benefit that enables consumers to recognize the image of an individual positively. Therefore, we expect that the donation level in CRM will be perceived by the size of the benefit regardless of consumer support, and the interaction effect between the donation level and consumer support will occur only when there are no self-expressive cues. This is because in the situation where self-expressive cues are presented, the donation level will be perceived as a benefit regardless of consumer support. Based on this, we derived the following hypothesis:

H5. When self-expressive cues are presented, the interaction effect of donation level and consumer support on consumer response will be diminished.

\section{Study 1}

\subsection{Data collection and sample}

Study 1 was conducted to examine the effect of consumer support on consumer perceptions (benefit versus monetary sacrifice) regarding the donation level in CRM. Using 162 US citizens recruited through Amazon Mechanical Turk (MTurk), we use Study 1 to test hypotheses 1-4. Of the participants, $49.4 \%$ were male $(n=80)$, and their average age was $38.50(\mathrm{SD}=11.89$, range of age $=22-78$ ). They were randomly assigned to one of two groups based on the donation level.

\subsection{Development of experimental stimuli}

Experimental stimuli were produced in two different formats depending on the donation level. We selected ice cream as the product category to be used in the experiment based on the work of Hamby (2016), and selected the cause area as the protection of cultural properties based on the work of Yoo and Lee (2018). Following the design of Yoo et al. (2018), donation level was set to $5 \%$ of the regular price for the low-level group and $40 \%$ of the regular price for the high-level group. As a result of the pretest $(\mathrm{n}=42)$, subjects perceived $40 \%$ donations $(\mathrm{M}=5.23)$ as a higher level than $5 \%$ donations $(\mathrm{M}=3.05 ; \mathrm{t}=4.58, \mathrm{p}<.001)$.

\subsection{Methods}

Participants first received a print advertisement of an ice cream brand that encouraged consumers to participate in CRM and contained information on donation levels and cause activities (see Appendix). After viewing the advertisement, participants responded to manipulation check items of donation level (two items from Koschate-Fischer et al. (2016); $\alpha=.873$ ), consumer support (four items from Arnett et al. (2003); $\alpha=.840$ ), participation intentions (four items from Grau and Folse (2007); $\alpha=$.925), perceived benefits (three items from Andrews et al. (2014) and Green and Peloza (2014); $\alpha=.887$ ), perceived monetary sacrifice (two items from Yoo et al. (2018); $\alpha=.880$ ), and demographic items. All items were measured on a 7-point Likert scale. Cronbach's Alpha of all items was over .800, which means that the internal consistency of the measured items was high.

\subsection{Results}

\subsubsection{Manipulation check}

The results of the one-way ANOVA test to check the donation level manipulation showed that the influence of the donation level was significant $(\mathrm{F}=88.99, \mathrm{p}<.001)$. Participants perceived that the donation level of $40 \%(\mathrm{M}=5.57)$ was higher than $5 \%$ of the regular price $(\mathrm{M}=3.48)$. Therefore, manipulation of the donation level was successful.

\subsubsection{Perceived benefits}

In order to verify our hypotheses, a regression analysis of perceived benefits was conducted by inputting donation level, consumer support (meancentered; $M=4.17, S D=1.00$ ), and interaction variables of each factor. The results showed that the donation level had significant main effects $(\beta=.90,=2.78, \mathrm{p}<.01)$, demonstrating that the higher the donation level, the more the subjects perceived it as beneficial. In addition, the interaction effect between the donation level and consumer support was significant $(\beta=1.01,=3.08, \mathrm{p}<.01)$. To analyze this, we performed spotlight analysis (Aiken et al. 1991), which showed that participants with high-level consumer support perceived more benefits when donation levels were low $(\mathrm{M}=4.26)$ as opposed to high $(\mathrm{M}=5.77)(\beta=.95, \mathrm{t}=2.83, \mathrm{p}<.01)$, while for those participants with low-level consumer support, there were no significant differences in perceived benefits based on donation level (low donation level: 3.67 vs. high donation level: 3.20; $\beta=-.52, \mathrm{t}=-1.54, \mathrm{p}>.1$ ). Thus, $\mathrm{H} 1$ was supported.

\subsubsection{Perceived monetary sacrifice}

As a result of the regression analysis on perceived monetary sacrifice, the main effect of the donation level was significant $(\beta=1.15,=3.61, p<.001)$. The higher the donation level, the larger the perceived monetary sacrifice. Further, the interaction effect between donation level and consumer support was significant $(\beta=-.85,=-2.66, \mathrm{p}<.01)$. The spotlight 
analysis showed that participants with high-level consumer support did not perceive the monetary sacrifice differently based on donation level (low donation level: 4.33 vs. high donation level: 4.00; $\beta=.43, t=1.24, p>.1$ ), while those with low-level consumer support perceived more monetary sacrifices when the donation levels were high $(M=5.25)$ as opposed to when they were low $(M=4.17)$ $(\beta=1.73, \mathrm{t}=4.99, \mathrm{p}<.001)$. Thus, $\mathrm{H} 2$ was supported.

\subsubsection{Participation intentions}

The results of the regression analysis on the participation intentions showed a significant main effect of the donation level $(\beta=1.01, t=3.13$, $\mathrm{p}<.01$ ), indicating that the higher the level of the donation, the more participants are willing to participate in CRM. In addition, the interaction effect between the donation level and CSR support was significant $(\beta=1.10, t=3.37, p<.01)$. As a result of the spotlight analysis, participants with high-level consumer support had more intentions to participate when the donation level was high $(M=5.68)$ than when low $(\mathrm{M}=4.35 ; \beta=.97, \mathrm{t}=2.81, \mathrm{p}<.01)$, while those with low-level consumer support had more intentions to participate when the donation level was low $(\mathrm{M}=4.50)$ than when it was high $(\mathrm{M}=3.34 ; \beta=-.68, \mathrm{t}=-1.97, \mathrm{p}=.051)$. Thus, $\mathrm{H} 3$ was supported.

\subsubsection{Mediation analysis}

To verify hypothesis 5 confirming the mechanism of the donation level effect, we conducted mediation analyses. In order to clearly identify the path between each variable, bootstrapping analyses using model 4 of the PROCESS macro was carried out centering on CSR support $(10,000$ resamples) (Preacher and Hayes 2008; Zhao et al. 2010).

The results (see Table 1) showed that for the participants with high consumer support, the indirect effect of perceived benefits (indirect effect $=1.45,95 \%$ CI: .21 to 2.80 ) rather than perceived monetary sacrifice (indirect effect $=-.14$,
95\% CI: -1.00 to .55$)$ was significant. However, for those with low-level consumer support, the indirect effect of perceived monetary sacrifice (indirect effect $=-.84,95 \% \mathrm{CI}:-4.39$ to -.01$)$ rather than perceived benefits (indirect effect $=-.43,95 \% \mathrm{CI}$ : -2.47 to 1.87 ) was significant. This means that consumers with high consumer support, who perceive the donation level as beneficial, have more positive intentions to participate in CRM as the donation level increases, whereas those with low-level consumer support, who perceive the donation level as a monetary sacrifice, have more negative intentions as donation levels increase. Therefore, H4 was supported.

\section{Study 2}

\subsection{Data collection and sample}

Study 2 was conducted to examine whether donation levels, consumer support, and selfexpressive cues influence consumer perception of benefits and monetary sacrifice. Tested hypothesis 5 , we implemented a 2 (donation level: high vs. low) x 2 (consumer support: high vs. low) x 2 (selfexpressive cues: yes vs. no) between subject design. Our sample size consisted of 217 US citizens hired and financially rewarded through Amazon MTurk. Of those participants, $44.2 \%$ were male $(n=96)$, and their average age was $39.23(\mathrm{SD}=10.68$, range of age $=21-74)$. These participants were randomly assigned to one of eight groups according to the three variables.

\subsection{Development of experimental stimuli}

Experimental stimuli were produced in four different formats depending on donation level and self-expressive cues. According to the study of Yoo et al. (2018), coffee was selected as a product category, and Starbucks was selected as a company that performs CRM. The donation level was set in the same manner as in Study 1 (low level: $5 \%$ of regular

Table 1. Mediation analysis results (Study 1).

\begin{tabular}{lllll}
\hline IV & MV & DV & Indirect effect & $95 \%$ CI \\
\hline High consumer support & & & & \\
\hline Donation level & Perceived benefits & Participation intentions & 1.45 & $.21-2.80$ \\
& Perceived monetary sacrifice & & -.17 & $-1.00-.55$ \\
\cline { 2 - 4 } & & & & -.43 \\
Low consumer support & & Participation intentions & -.84 & $-2.47-1.87$ \\
\hline Donation level & Perceived benefits & & -.84 & -.01 \\
& Perceived monetary sacrifice & & & $-4.39 \sim$ \\
\hline
\end{tabular}


price vs. high level: $40 \%$ of regular price). Selfexpressive cues were manipulated through social observability according to Kristofferson et al. (2014). Specifically, in the condition of presenting selfexpressive cues, the stimulation was set as coffee is provided to consumers through a paper cup with a new design instead of through the existing paper cup. Starbucks' "Red cup" served as the "new design" paper cup (see Appendix), as consumers that drinking coffee from it are able to signal their CRM participation to others. As a result of the pretest $(n=40)$, the subjects perceived the selfexpression value higher when they were served coffee with the new paper cup $(\mathrm{M}=4.83)$ than when they were offered coffee in the existing paper cup $(\mathrm{M}=3.20 ; \mathrm{t}=4.45, \mathrm{p}<.001)$.

\subsection{Methods}

Participants first performed tasks related to consumer support. Consumer support was manipulated rather than measured, unlike Study 1. Based on Kim and Choi (2020), Yoo and Lee (2018), Yoon et al. (2006), and Zasuwa (2017), we presented nine cause activities to participants (e.g., saving the starving children, fighting cancer, and environmental protection and conservation), and participants responded to the items asking their degree of support for each activity (four items from Arnett et al. (2003); $\alpha=.820$ ). We then reminded participants of the activity once again by asking high-level consumer support participants to write down the activity that they supported most strongly, and by asking low-level consumer support participants to write down the activity that they supported the least.

After completing the consumer support tasks, the participants were presented with a scenario involving Starbucks executing a cause activity through CRM along the lines of those mentioned in the consumer support task, and were provided with print advertisements for Starbucks CRM campaigns.

The advertisement contained stimuli developed through pretest. After viewing the advertisement, participants responded to items about donation levels (two items from Koschate-Fischer et al. (2016); $\alpha=.923$ ), self-expressive cues manipulation checks (three items from Baek et al. (2010); $\alpha=.961$ ), participation intentions (four items from Grau and Folse (2007); $\alpha=.950$ ), perceived benefits (three items from Andrews et al. (2014) and Green and Peloza (2014); $\alpha=.917)$, perceived monetary sacrifice (two items from Yoo et al. (2018); $\alpha=.902$ ), brand attitude (four items from Folse et al. (2013); $\alpha=.988)$, and cause-brand fit (single item). Finally, they responded to demographic items. Cronbach's Alpha of the items used in Study 2 had a high internal consistency of more than .800 .

\subsection{Results}

The results of Study 2 were analyzed using a 2 (donation level: high vs. low) $x 2$ (consumer support: high vs. low) x 2 (self-expressive cue: yes vs. no) ANCOVA. In order to minimize the external influence that can be caused by using an actual brand as an experimental stimulus, a brand attitude toward Starbucks and a cause-brand fit were used as covariates.

\subsubsection{Manipulation check}

With respect to results of $2 \times 2 \times 2$ ANCOVA to check the manipulation of consumer support, the main effect of consumer support was significant $(\mathrm{F}=48.252, \mathrm{p}<.001)$. High-level consumer support participants $(\mathrm{M}=5.22)$ supported the cause more than low-level participants $(\mathrm{M}=3.81)$. The influence of other variables was not significant (all, $\mathrm{p}>.1$ ).

As a result of the $2 \times 2 \times 2$ ANCOVA for donation level, the main effect of the donation level was significant $(\mathrm{F}=67.784, \mathrm{p}<.001)$. Participants perceived $40 \%(M=5.31)$ as a higher donation level than $5 \%$ $(\mathrm{M}=3.40)$. The influence of other variables was not significant (all, $\mathrm{p}>.1$ ).

As a result of the $2 \times 2 \times 2$ ANCOVA for selfexpressive values, participants perceived higher self-expressive values when the cues were presented $(M=5.04)$ than when they were not $(\mathrm{M}=3.68 ; \mathrm{F}=29.734, \mathrm{p}<.001)$. The influence of other variables was not significant (all, $\mathrm{p}>.1$ ). This means that manipulations of consumer support, donation levels, and self-expressive cues were successful.

\subsubsection{Perceived benefits}

As a result of the ANCOVA on perceived benefits, the main effect of donation levels was significant $(\mathrm{F}=16.448, \mathrm{p}<.001)$. Participants perceived more benefits when the donation level was high $(M=5.08)$ than low $(M=4.17)$. The main effects of the other variables were not significant. More importantly, the interaction effect between the donation level, consumer support, and self-expressive cues was significant $(\mathrm{F}=4.786, \mathrm{p}<.05)$. 

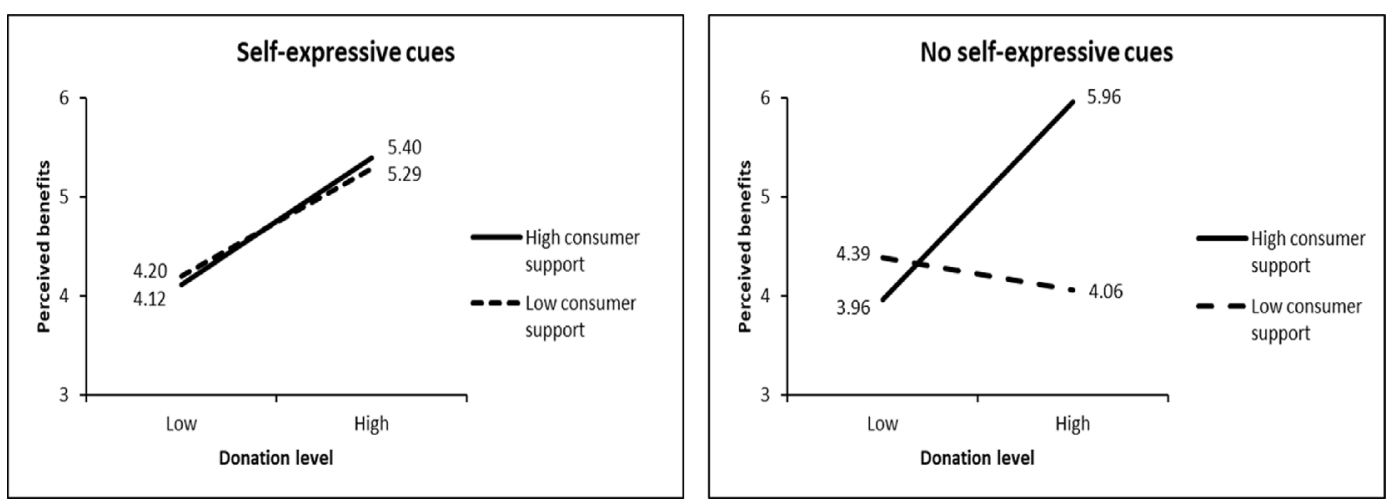

Fig. 1. Interaction effects on perceived benefits.

Contrast analysis to assess the interaction effect (see, Fig. 1) showed that when self-expressive cues were presented, both participants with high consumer support (low donation level: 4.12 vs. high donation level: 5.40; $\mathrm{F}=7.606, \mathrm{p}<.01$ ) and those with low consumer support (low donation level: 4.20 vs. high donation level: 5.29; $\mathrm{F}=7.016, \mathrm{p}<.01$ ) perceived more benefits as the donation level increased. However, when self-expressive cues were not presented, participants with high consumer support perceived more benefits $(\mathrm{F}=12.963, \mathrm{p}<$. $001)$ in the high donation level condition $(M=5.96)$ than in the low donation level condition $(\mathrm{M}=3.96)$, whereas those with low consumer support did not perceive benefits differently on the basis of donation level (low donation level: 4.39 vs. high donation level: 4.06; $\mathrm{F}=.829, \mathrm{p}>.1)$.

\subsubsection{Perceived monetary sacrifice}

The ANCOVA on perceived monetary sacrifice showed the main effect of self-expressive cues was significant $(\mathrm{F}=7.854, \mathrm{p}<.01)$, indicating that participants perceived more monetary sacrifice when self-expressive cues were not presented $(\mathrm{M}=4.23)$ than when they were presented
$(\mathrm{M}=3.62)$. In addition, the interaction effect of the three variable levels was significant $(F=4.968$, $\mathrm{p}<.05$ ). The contrast analysis (see, Fig. 2) showed that when self-expressive cues were presented, the perceived monetary sacrifice of the participants with high consumer support (low donation level: 3.39 vs. high donation level: $3.80 ; \mathrm{F}=1.410, \mathrm{p}>.1$ ) and those with low consumer support (low donation level: 3.77 vs. high donation level: 3.52; $\mathrm{F}=.358, \mathrm{p}>.1$ ) did not differ by donation level. However, when self-expressive cues were not presented, perceived monetary sacrifice of participants with high consumer support did not depend on donation levels (low donation level: 3.96 vs. high donation level: 3.94; $F=.018, \mathrm{p}>$. 1), whereas those with low consumer support perceived more monetary sacrifice from high-level donations $(\mathrm{M}=5.08)$ than from low-level donations $(\mathrm{M}=3.96 ; \mathrm{F}=6.592, \mathrm{p}<.05)$.

\subsubsection{Participation intentions}

The results of ANCOVA on participation intentions showed that the main effects of selfexpressive cues (non-presentation: 4.29 vs. presentation: $4.71 ; \mathrm{F}=3.777, \mathrm{p}=.053$ ), consumer
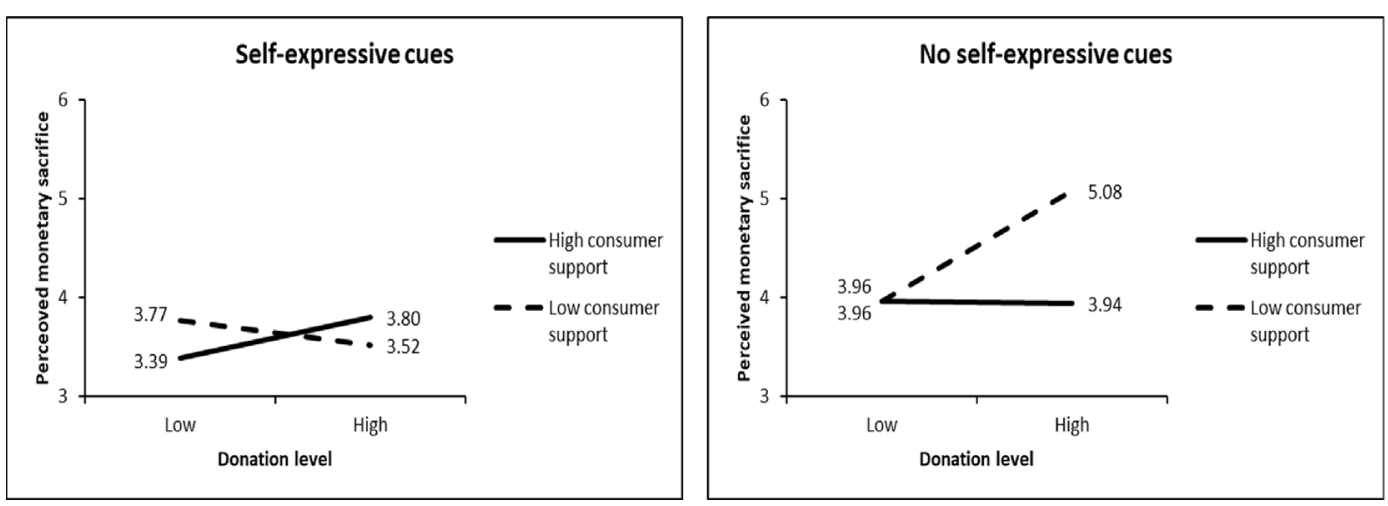

Fig. 2. Interaction effects on perceived monetary sacrifice. 

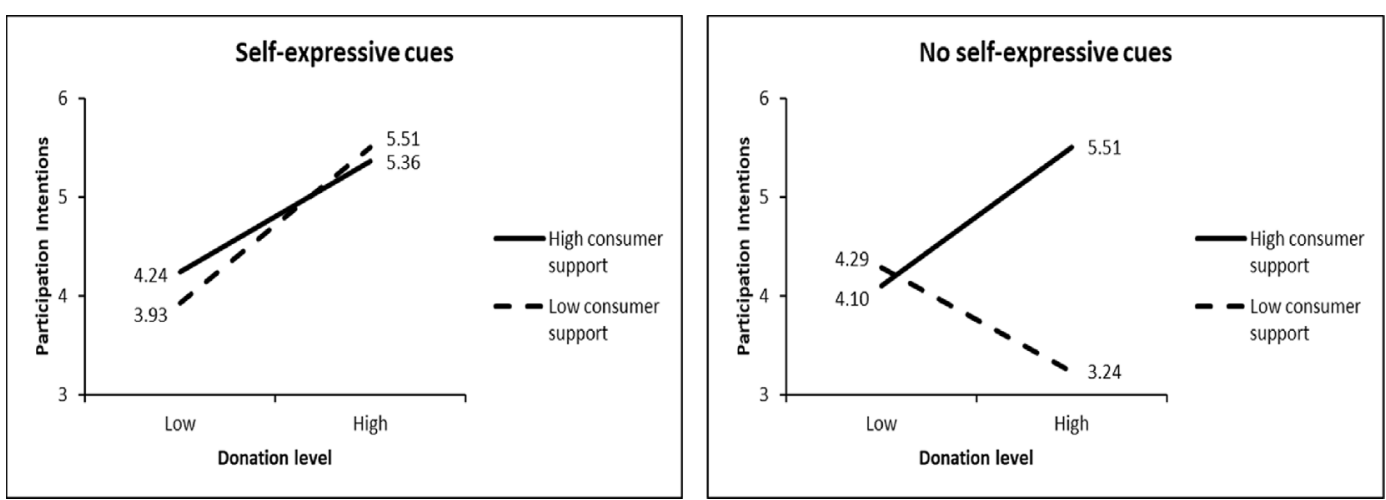

Fig. 3. Interaction effects on participation intentions.

support (low: 4.21 vs. high: $4.80 ; \mathrm{F}=6.118, \mathrm{p}<.05$ ), and donation level (low: 4.14 vs. high: 4.90; $\mathrm{F}=10.062$, $\mathrm{p}<.01$ ) was significant. More importantly, the interaction effect of the three variables was significant $(F=12.220, p<.01)$. Results of the contrast analysis (see, Fig. 3) revealed that when self-expressive cues were presented, both participants with high consumer support (low donation level: 4.24 vs. high donation level: 5.36 ; $\mathrm{F}=4.557$, $\mathrm{p}<.05$ ) and those with low consumer support (low donation level: 3.93 vs. high donation level: 5.51; $\mathrm{F}=13.132, \mathrm{p}<.001$ ) had more positive participation intentions as donation level increased. However, when self-expressive cues were not provided, participants with high consumer support had more positive intentions to participate in high-level donation $(\mathrm{M}=5.51)$ than in low-level donation $(\mathrm{M}=4.10 ; \mathrm{F}=9.332, \mathrm{p}<.01)$, whereas those with low consumer support had more positive intentions to participate in low-level donation $(\mathrm{M}=4.29)$ than in high-level donation $(\mathrm{M}=3.24$; $\mathrm{F}=6.189, \mathrm{p}<.05)$.

\subsubsection{Mediation analysis}

To confirm the mechanism of this study, we conducted mediation analyses centering on selfexpressive cues and consumer support (model 4 of PROCESS macro; 10,000 resamples) (Preacher and Hayes 2008; Zhao et al. 2010).

As results of the analysis (see Table 2), in the selfexpression cues and high-level consumer support condition, the indirect effect of perceived benefits (indirect effect $=1.00,95 \%$ CI: .40 to 1.68 ) rather than perceived monetary sacrifice (indirect effect $=.01,95 \%$ CI: -.11 to .21 ) was significant. Further, in the self-expressive cues and low consumer support condition, perceived benefits (indirect effect $=.92,95 \%$ CI: .32 to 1.54 ) rather than perceived monetary sacrifice (indirect effect $=-.02$, 95\% CI: -.21 to .04), was significant. This means that if self-expressive cues are presented, regardless of consumer support, consumers will have more positive intentions to participate in CRM when donation levels are high as opposed to when they are low because they perceive the donation

Table 2. Mediation analysis results (Study 2).

\begin{tabular}{|c|c|c|c|c|}
\hline IV & MV & DV & Indirect effect & $95 \% \mathrm{CI}$ \\
\hline \multicolumn{5}{|c|}{ Self-expressive cues and High consumer support } \\
\hline \multirow[t]{2}{*}{ Donation level } & Perceived benefits & Participation intentions & 1.00 & $.40-1.68$ \\
\hline & Perceived monetary sacrifice & & .01 & $-.11-.21$ \\
\hline \multicolumn{5}{|c|}{ Self-expressive cues and low consumer support } \\
\hline \multirow[t]{2}{*}{$\overline{\text { Donation level }}$} & Perceived benefits & Participation intentions & .92 & $.32-1.54$ \\
\hline & Perceived monetary sacrifice & & -.02 & $-.21-.04$ \\
\hline \multicolumn{5}{|c|}{ No self-expressive cues and High consumer support } \\
\hline \multirow[t]{2}{*}{ Donation level } & Perceived benefits & Participation intentions & 1.27 & $.60-2.09$ \\
\hline & Perceived monetary sacrifice & & .00 & $-.11-.13$ \\
\hline \multicolumn{5}{|c|}{ No self-expressive cues and low consumer support } \\
\hline \multirow[t]{2}{*}{ Donation level } & Perceived benefits & Participation intentions & -.26 & $-1.00-.11$ \\
\hline & Perceived monetary sacrifice & & -.60 & $-1.44 \sim-.12$ \\
\hline
\end{tabular}


level as beneficial rather than as a monetary sacrifice.

In the no self-expressive cues and high consumer support condition, the indirect effect of perceived benefits (indirect effect $=1.27,95 \%$ CI: .60 to 2.09 ) rather than perceived monetary sacrifice (indirect effect $=.00,95 \%$ CI: -.11 to .13 ) was significant. However, in the no self-expressive cues and low consumer support condition, perceived monetary sacrifice (indirect effect $=-.60,95 \%$ CI: -1.44 to -.12) rather than perceived benefit (indirect effect $=-.26,95 \% \mathrm{CI}:-1.00$ to .11$)$ was significant. This is because, as a result of Study 1, when selfexpressive cues are not presented, consumers with high consumer support who perceive the donation level as a benefit will have more positive intentions to participate in CRM as donation levels increase, while those with low consumer support who perceive the donation level as a monetary sacrifice will have negative intentions to participate in CRM as donation levels increase. This means that Hypothesis 5 was supported.

\section{Discussion}

The purpose of this study was to examine whether consumer perception about CRM donation levels is affected by consumer support and self-expressive cues. The results confirmed through the two studies are summarized as follows. First, it was found that consumer perceptions of the donation level depend on consumer support. When consumer support for a cause domain is high, consumers perceive the donation level as beneficial, so the level of donation has a positive effect on a consumer's intention to participate. However, when consumer support is low, they perceive the donation level as a monetary sacrifice, so that the level of donation has a negative effect on intention to participate. This means, as we predicted, that the impact of the donation level on consumer participation intentions in CRM is determined by the perceived benefits and perceived monetary sacrifice according to the level of consumer support.

Second, Study 2 showed that when self-expressive cues were presented, the donation level has a positive effect on intention to participate because consumers perceive the level of donation as a benefit regardless of their support for the cause domain. This means that the presentation of self-expressive cues dilutes the interactive effect of donation level and consumer support. Thus, in Study 2, we confirmed the boundary condition of the interaction effect.
This study has the following academic implications. First, this study revealed that the difference in participation intentions according to the donation level presented in CRM is determined by the consumer's perceptions of the donation amount (perceived benefit/monetary sacrifice), and that the type of consumer perception is moderated by consumer support for cause domain. In other words, our research contributed to the study of CRM donation by examining the differential effect of the donation level in CRM and its mechanisms, which was lacking interest in previous studies. This study has contributed to the expansion of research related to donation levels through the application of different research areas, such as donation level and consumer support. Furthermore, this study also proposed a way (self-expressive cues) to lower consumer perceptions of monetary sacrifice as a means of avoiding negative impacts on donation levels. We expected that lowering consumer perceptions of monetary sacrifice would increase participation intentions, and confirmed that selfexpressive cues lower consumer perceptions of monetary sacrifice, thus increasing participation intentions.

This study also provides some practical implications. According to previous studies, as the level of donation presented by a company increases, consumers experience what has been denoted "warm glow" because they think that the benefits provided to others increase. However, they may think that the monetary costs to be sacrificed also increase as a consequence of this (Yoo et al. 2018). This means that CRM can have negative effects, which are undesirable in the context of business. In this vein, this study investigated the mechanisms for positive and negative effects according to donation levels, which were not explained in previous studies, and examined the role of consumer support as a factor influencing these effects. The results show that consumers with high support for the cause area perceive the donation level as a benefit, meaning that the donation level is positively-related to a consumer's intention to participate. However, consumers with low support perceive the donation level as monetary sacrifice, thus leading to a negative relationship between the donation level and the participation intentions of a consumer. Therefore, in setting the level of donation, companies should understand the characteristics of consumers and find the cause areas for which consumers express highlevel support. To do this, companies must collect and analyse information about consumers to find out what their interests and needs are. Furthermore, 
companies should consider ways to increase consumer support for the cause domains when implementing CRM. For example, if companies can increase consumer support by emphasizing the importance and necessity of the cause domains, consumers will perceive the level of donation as benefits. This will be an effective way to induce a favorable response from consumers in a company's CRM implementation. Finally, this study provides a method to minimize the perception of monetary sacrifice that negatively affects consumers' intentions to participate in CRM. For companies, increasing donation levels means that the burden of the company increases (Strahilevitz 1999). If consumers perceive a donation as a monetary sacrifice, even though companies are burdened by increasing donation levels, it means that the corporate CRM strategy of has failed. In this regard, the results of this study show that the self-expressive cues included in CRM-related messages reduce perceptions of monetary sacrifice, thereby increasing consumers' intentions to participate in CRM. In other words, if companies provide self-expressive cues when implementing CRM, they can improve the possibility of CRM success. Therefore, companies need to develop a variety of ways to provide consumers with self-expressive cues. For example, previous studies show that product package design (Kumar and Noble 2016), use of badges (Kristofferson et al. 2014), and scarcity of products (Bian and Forsythe 2012) can be self-expressive cues. Companies must establish a successful CRM strategy by delivering self-expressive cues to consumers in these various ways. Thus, these results provide implications that can lower the possibility of failure and increase efficiency in the use of corporate CRM strategies.

Although this study provides various implications, it has the following limitations. First, we used relatively inexpensive product categories (ice cream and coffee) as stimulants for the experiment. In future research, it is necessary to conduct experiments that consider product price. This is because product price can affect consumer involvement and perceived monetary sacrifice. Therefore, it is necessary to consider this and conduct experiments on products of various price ranges in future research. Moreover, it is possible that the product categories used in our study made the participants focus on the hedonic values or unhealthy characteristics of the products. Future research needs to conduct experiments by reflecting product types such as hedonic products and utilitarian products, and healthy food and unhealthy food. Second, in this study, the presentation method of donation levels was presented as a ratio (\%). Previous studies mention that the presentation method of donation level ( $\%$ vs. \$) can influence consumer responses differently (Arora and Henderson 2007; Strahilevitz 1999). Therefore, it is necessary to check the influence of the donation level presentation method in future research. Finally, we used the paper cup design as an experimental stimulus to provide self-expressive value to consumers. In future research, it is necessary to provide self-expressive cues to consumers in various ways. For example, previous studies have suggested that the badges provided to consumers (Kristofferson et al. 2014) or the scarcity of products (Bian and Forsythe 2012; Song and Lee 2013) can provide consumers with self-expressive value. Future research should investigate whether these strategies can also reduce consumers' perceived level of monetary sacrifice.

\section{Funding}

This research received no external funding.

\section{Conflict of interest}

The authors declare no conflicts of interest.

\section{Appendix. Examples of Experimental Stimuli}

Study 1 (high donation level condition)

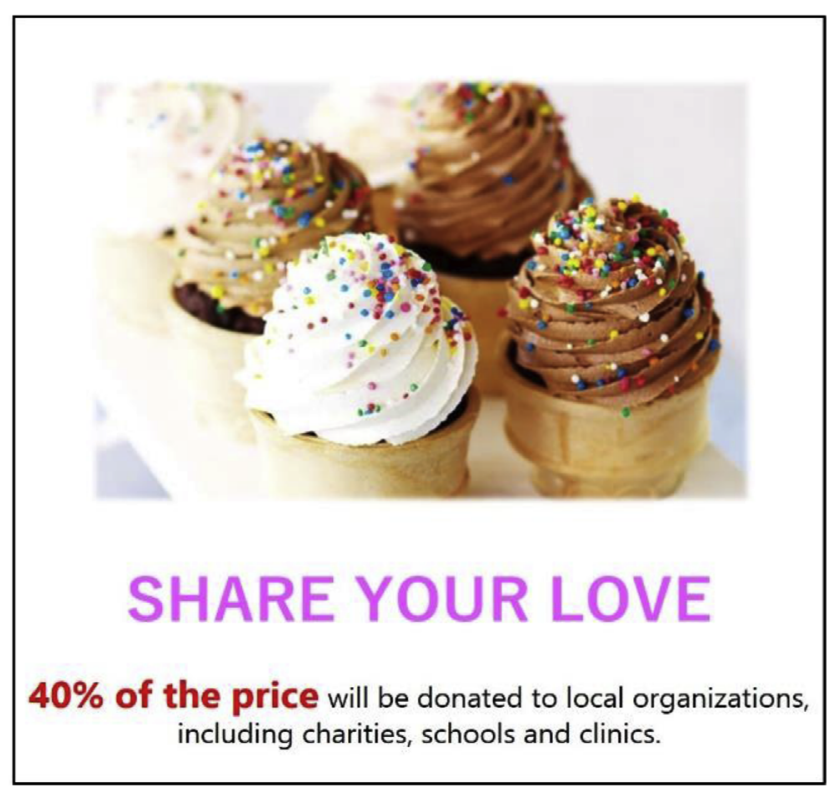


Study 2

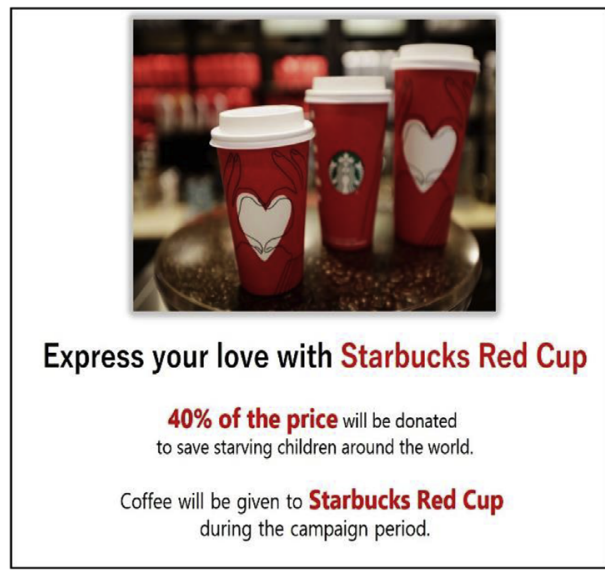

(a) Self-expressive cues and high donation level condition

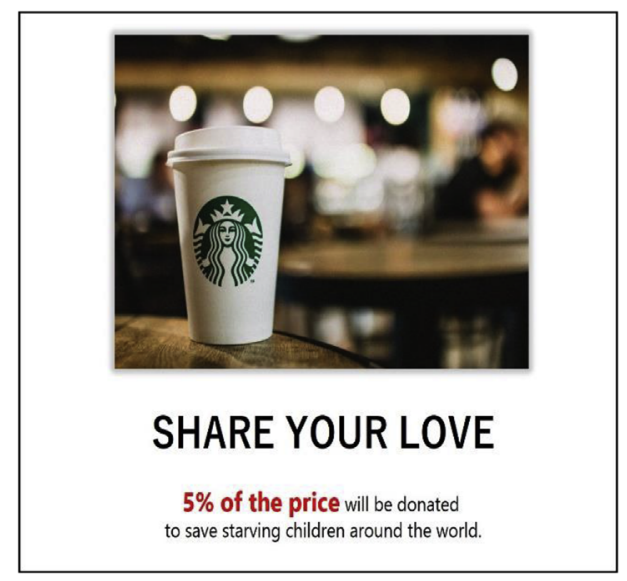

(b) No self-expressive cues and low donation level condition

\section{References}

Ahuvia, Aaron C. (2005), "Beyond the extended self: Loved objects and consumers' identity narratives," Journal of Consumer Research, 32 (1), 171-84.

Aiken, Leona S., Stephen G. West, and Raymond R. Reno (1991), "Multiple regression: Testing and interpreting interactions," Sage.

Andreoni, James (1989), "Giving with impure altruism: Applications to charity and Ricardian equivalence," Journal of Political Economy, 97 (6), 1447-58.

Andrews, Michelle, Xueming Luo, Fang Zheng, and Jaakko Aspara (2014), "Cause marketing effectiveness and the moderating role of price discounts," Journal of Marketing, 78 (6), 120-42.

Aquino, Karl and Americus Reed II (2002), "The self-importance of moral identity," Journal of Personality and Social Psychology, 83 (6), 1423-40.

Arnett, Dennis B., Steve D. German, and Shelby D. Hunt (2003), "The identity salience model of relationship marketing success: The case of nonprofit marketing," Journal of Marketing, 67 (2), 89-105.

Arora, Neeraj and Ty Henderson (2007), "Embedded premium promotion: Why it works and how to make it more effective," Marketing Science, 26 (4), 514-31.

Baek, Tae Hyun, Jooyoung Kim, and Jay Hyunjae Yu (2010), "The differential roles of brand credibility and brand prestige in consumer brand choice," Psychology and Marketing, 27 (7), 662-78.

Barone, Michael J., Anthony D. Miyazaki, and Kimberly A. Taylor (2000), "The influence of cause-related marketing on consumer choice: Does one good turn deserve another?" Journal of the Academy of Marketing Science, 28 (2), 248-62.

Baskentli, Sara, Sankar Sen, Shuili Du, and C.B. Bhattacharya (2019), "Consumer reactions to corporate social responsibility: The role of CSR domains," Journal of Business Research, 95, 502-13.

Belk, Russell W. (1988), "Possessions and the extended self," Journal of Consumer Research, 15 (2), 139-68.

Berger, Ida E., Peggy H. Cunningham, and Robert V. Kozinets (1999), "Consumer persuasion through cause-related advertising," ACR North American Advances.

Berger, Jonah and Chip Heath (2007), "Where consumers diverge from others: Identity signaling and product domains," Journal of Consumer Research, 34 (2), 121-34.

Bhattacharya, C.B., Sankar Sen, and Daniel Korschun (2011), "Leveraging corporate responsibility: The stakeholder route to maximizing business and social value," Cambridge University Press.

Bian, Qin and Sandra Forsythe (2012), "Purchase intention for luxury brands: A cross cultural comparison," Journal of Business Research, 65 (10), 1443-51.

CauseGood. (2017), "The case for cause marketing - statistics for businesses \& nonprofits," CauseGood.

Chan, Cindy, Jonah Berger, and Leaf Van Boven (2012), "Identifiable but not identical: Combining social identity and uniqueness motives in choice," Journal of Consumer Research, 39 (3), 561-73.

Chang, Chun-Tuan and Yu-Kang Lee (2008), "The roles of product characteristics and framing effects in the effectiveness of cause-related marketing," ACR North American Advances.

Chen, Rong, Song Su, and Feng He (2014), "Does cause congruence affect how different corporate associations influence consumer responses to cause-related marketing?" Australian Journal of Management, 39 (2), 191-206.

Chernev, Alexander, Ryan Hamilton, and David Gal (2011), "Competing for consumer identity: Limits to self-expression and the perils of lifestyle branding," Journal of Marketing, 75 (3), 66-82.

Coleman, Joshua T., Marla B. Royne, and Kathrynn R. Pounders (2020), "Pride, guilt, and self-regulation in cause-related marketing advertisements," Journal of Advertising, 49 (1), 34-60.

Creyer, Elizabeth H. and William T. Ross Jr. (1997), "Tradeoffs between price and quality: How a value index affects," Journal of Consumer Affairs, 31 (2), 280-302.

Dahl, Darren W. and Anne M. Lavack (1995), "Cause-related marketing: Impact of size of corporate donation and size of cause-related promotion on consumer perceptions and participation," in AMA winter educators' conference proceedings, Vol. 6.

Drumwright, Minette E. (1996), "Company advertising with a social dimension: The role of noneconomic criteria," Journal of Marketing, 60 (4), 71-87. 
Elliott, Richard (1997), "Existential consumption and irrational desire," European Journal of Marketing, 31 (3/4), 285-96.

Escalas, Jennifer Edson and James R. Bettman (2005), "Self-construal, reference groups, and brand meaning," Journal of Consumer Research, 32 (3), 378-89.

Folse, Judith Anne Garretson, Scot Burton, G. Richard, and Netemeyer. (2013), "Defending brands: Effects of alignment of spokescharacter personality traits and corporate transgressions on brand trust and attitudes," Journal of Advertising, $42(4), 331-42$.

Fries, Anne J. (2010), "The effects of cause-related marketing campaign characteristics," Marketing ZFP, 32 (JRM 2), 145-57.

Gentina, Elodie, Margaret K. Hogg, and Mototaka Sakashita (2017), "Identity (Re) construction through sharing: A study of mother and teenage daughter dyads in France and Japan," Journal of Retailing and Consumer Services, 37, 67-77.

Grau, Stacy Landreth and Judith Anne Garretson Folse (2007), "Cause-related marketing (CRM): The influence of donation proximity and message-framing cues on the less-involved consumer," Journal of Advertising, 36 (4), 19-33.

Green, Todd and John Peloza (2014), "Finding the right shade of green: The effect of advertising appeal type on environmentally friendly consumption," Journal of Advertising, 43 (2), $128-41$.

Habel, Johannes, Marie Schons Laura, Alavi Sascha, and Wieseke Jan (2016), "Warm glow or extra charge? The ambivalent effect of corporate social responsibility activities on customers' perceived price fairness," Journal of Marketing, $80(1), 84-105$.

Hajjat, Mahmood M. (2003), "Effect of cause-related marketing on attitudes and purchase intentions: The moderating role of cause involvement and donation size," Journal of Nonprofit \& Public Sector Marketing, 11 (1), 93-109.

Haley, Eric (1996), "Exploring the construct of organization as source: Consumers' understandings of organizational sponsorship of advocacy advertising," Journal of Advertising, 25 (2), 19-35.

Hamby, Anne (2016), "One for me, one for you: Cause-related marketing with buy-one give-one promotions," Psychology and Marketing, 33 (9), 692-703.

Hollenbeck, Candice R. and Andrew M. Kaikati (2012), "Consumers' use of brands to reflect their actual and ideal selves on Facebook," International Journal of Research in Marketing, 29 (4), 395-405.

Howie, Katharine, M., Yang Lifeng, Scott J. Vitell, Bush Victoria, and Vorhies Doug (2018), "Consumer participation in causerelated marketing: An examination of effort demands and defensive denial," Journal of Business Ethics, 147 (3), 679-92.

Huang, Min-Hsin, Zhao-Hong Cheng, and I-Chun Chen (2017), "The importance of CSR in forming customer-company identification and long-term loyalty," Journal of Services Marketing, 31 (1), 63-72.

Jeong, Hyun Ju, Hye-Jin Paek, and Mira Lee (2013), "Corporate social responsibility effects on social network sites," Journal of Business Research, 66 (10), 1889-95.

Kim, Yoojung and Sejung Marina Choi (2020), "When good becomes bad: The role of corporate crisis and issue congruence," International Journal of Advertising, 39 (4), 571-86.

Kim, Heejung S. and David K. Sherman (2007), "Express yourself": Culture and the effect of self-expression on choice," Journal of Personality and Social Psychology, 92 (1), 1-11.

Koschate-Fischer, Nicole, Isabel V. Huber, and Wayne D. Hoyer (2016), "When will price increases associated with company donations to charity be perceived as fair?" Journal of the Academy of Marketing Science, 44 (5), 608-26.

Kotler, Philip and Nancy Lee (2008), "Corporate social responsibility: Doing the most good for your company and your cause," John Wiley \& Sons.

Kristofferson, Kirk, Katherine White, and John Peloza (2014), "The nature of slacktivism: How the social observability of an initial act of token support affects subsequent prosocial action," Journal of Consumer Research, 40 (6), 1149-66.
Kumar, Minu and Charles H. Noble (2016), "Beyond form and function: Why do consumers value product design?" Journal of Business Research, 69 (2), 613-20.

Kuo, Andrew and Dan Hamilton Rice (2015), "The impact of perceptual congruence on the effectiveness of cause-related marketing campaigns," Journal of Consumer Psychology, 25 (1), $78-88$.

Lafferty, Barbara A. (1996), "Cause-related marketing: Does the cause make a difference in consumers' attitudes and purchase intentions toward the product," in Working paper. Department of Marketing, Florida State Univ.

Landrum, Sarah (2017), "Millennials driving brands to practice socially responsible marketing," in Fobes, Vol. July.

Leary, Mark R. and Robin M. Kowalski (1990), "Impression management: A literature review and two-component model," Psychological Bulletin, 107 (1), 34-47.

Lee, Chia-Lin (2017), "The impact of consumer evaluation on the cause-related marketing," Asia Marketing Journal, 19 (1), $1-17$.

Lee, Shinhyoung and Youjae Yi (2017), "Overcoming the cause marketing paradox: The effect of nostalgia on charitable giving and happiness," Asia Marketing Journal, 19 (3), 1-17.

Maity, Moutusy, Mayukh Dass, K. Naresh, and Malhotra. (2014), "The antecedents and moderators of offline information search: A meta-analysis," Journal of Retailing, 90 (2), 233-54.

Marin, Longinos and Salvador Ruiz (2007), "I need you too!" Corporate identity attractiveness for consumers and the role of social responsibility," "Journal of Business Ethics, 71 (3), 245-60.

Martínez, Eva and Teresa Montaner (2006), "The effect of consumer's psychographic variables upon deal-proneness," Journal of Retailing and Consumer Services, 13 (3), 157-68.

McWilliams, Abagail and Donald Siegel (2001), "Corporate social responsibility: A theory of the firm perspective," Academy of Management Review, 26 (1), 117-27.

Mohr, Lois A. and Deborah J. Webb (2005), "The effects of corporate social responsibility and price on consumer responses," Journal of Consumer Affairs, 39 (1), 121-47.

Mohr, Lois A., Deborah J. Webb, and Katherine E. Harris (2001), "Do consumers expect companies to be socially responsible? The impact of corporate social responsibility on buying behavior," Journal of Consumer Affairs, 35 (1), 45-72.

Moosmayer, Dirk C. and Alexandre Fuljahn (2010), "Consumer perceptions of cause related marketing campaigns," Journal of Consumer Marketing, 27 (6), 543-9.

Müller, Sarah S., Anne J. Fries, and Karen Gedenk (2014), "How much to give? The effect of donation size on tactical and strategic success in cause-related marketing," International Journal of Research in Marketing, 31 (2), 178-91.

Polonsky, Michael Jay and Richard Speed (2001), "Linking sponsorship and cause related marketing," European Journal of Marketing, 35 (11-1), 1361-89.

Powell, Shaun, John M.T. Balmer, T.C. Melewar, Klement Podnar, and Urša Golob (2007), "CSR expectations: The focus of corporate marketing," Corporate Communications: An International Journal, 12 (4), 326-40.

Preacher, Kristopher J. and Andrew F. Hayes (2008), "Asymptotic and resampling strategies for assessing and comparing indirect effects in multiple mediator models," Behavior Research Methods, 40 (3), 879-91.

Rajaguru, T.R. and P.K. Ganegoda (2017), "Facebook users and their engagement in prosocial activities in real life," International Journal of Integrative Sciences, 2 (1), 75-86.

Reed, Americus (2004), "Activating the self-importance of consumer selves: Exploring identity salience effects on judgments," Journal of Consumer Research, 31 (2), 286-95.

Rifkin, Jacqueline R. and Jordan Etkin (2019), "Variety in selfexpression undermines self-continuity," Journal of Consumer Research, 46 (4), 725-49.

Saenger, Christina, Veronica L. Thomas, and Jennifer Wiggins Johnson (2013), "Consumption-focused self- 
expression word of mouth: A new scale and its role in consumer research," Psychology and Marketing, 30 (11), 959-70.

Sela, Aner and Michal Maimaran (2013), "Variety as a preferencestrength signal," Available at: SSRN 1884439.

Sen, Sankar and Chitra Bhanu Bhattacharya (2001), "Does doing good always lead to doing better? Consumer reactions to corporate social responsibility," Journal of Marketing Research, 38 (2), 225-43.

Seo, HaeJin, TaeHo Song, and Li Wang (2020), "Effect of causerelated marketing in the Chinese market: Moderating effects of product type and regional characteristics," Asia Marketing Journal, 22 (3), 29-50.

Song, Doori and Joonghwa Lee (2013), "Balancing "We" and "I": Self-construal and an alternative approach to seeking uniqueness," Journal of Consumer Behaviour, 12 (6), 506-16.

Statista. (2018), "Sponsorship spending worldwide 2017-2018," Statista.

Strahilevitz, Michal (1999), "The effects of product type and donation magnitude on willingness to pay more for a charity-linked brand," Journal of Consumer Psychology, 8 (3), 215-41.

White, Katherine and Darren W. Dahl (2006), "To be or not be? The influence of dissociative reference groups on consumer preferences," Journal of Consumer Psychology, 16 (4), 404-14.

White, Katherine and Darren W. Dahl (2007), "Are all out-groups created equal? Consumer identity and dissociative influence," Journal of Consumer Research, 34 (4), 525-36.
Winterich, Karen Page and Michael J. Barone (2011), "Warm glow or cold, hard cash? Social identity effects on consumer choice for donation versus discount promotions," Journal of Marketing Research, 48 (5), 855-68.

Yamamoto, Toshiyuki, Li Cheng, and Takayuki Morikawa (2014), "An empirical analysis of the factors raising the interest in new shopping destinations," Journal of Retailing and Consumer Services, 21 (6), 950-7.

Yoo, Dongho, Jung-Ae Kim, and Sun-Jae Doh. (2018), "The dual processing of donation size in cause-related marketing (CRM): The moderating roles of construal level and emoticons," Sustainability, 10 (11), 4219.

Yoo, Dongho and Jieun Lee (2018), "The effects of corporate social responsibility (CSR) fit and CSR consistency on company evaluation: The role of CSR support," Sustainability, 10 (8), 2956.

Yoon, Yeosun, Zeynep Gürhan-Canli, and Norbert Schwarz (2006), "The effect of corporate social responsibility (CSR) activities on companies with bad reputations," Journal of Consumer Psychology, 16 (4), 377-90.

Zasuwa, Grzegorz (2017), "The role of company-cause fit and company involvement in consumer responses to CSR initiatives: A meta-analytic review," Sustainability, 9 (6), 1016.

Zhao, Xinshu, G. John, Lynch Jr., and Qimei Chen (2010), "Reconsidering baron and kenny: Myths and truths about mediation analysis," Journal of Consumer Research, 37 (2), 197-206. 